\title{
Preparation of Ni-Co Oxide Electrodes Containing Foreign Elements for Oxygen Evolution
}

\author{
Koji TACHIBANA*, Akihiro TSURUNO ${ }^{\dagger}$, Katsumichi KOBAYASHI ${ }^{\dagger \dagger}$ \\ and Kei-ichi NAGANUMA
}

Received February 12, 1993 ; Accepted March 19, 1993

\section{INTRODUCTION}

A variety of perovskite-type metal oxides have been given attention as candidate materials for the oxygen electrode without any use of precious metals such as platinum, rhodium and so on ${ }^{1,2)}$. They have been recognized in general to have high corrosion resistance and relatively high catalytic activity due to their large surface area. Among them, $\mathrm{Ni}$-Co oxides of spinel type $\mathrm{NiCO}_{2} \mathrm{O}_{4}$ have been studied systematically by $T$ seung et $a^{3 \sim 5)}$, who reported that the catalytic activity could be enhanced due to higher valent cations produced in the $\mathrm{Ni}$-Co oxides by $\mathrm{Li}$ doping. But, the chemical stability of Li or other IA elements doped $\mathrm{Ni}$-Co oxides, according to our reexamination, seems to be not enough to use for a long time in water electrolysis with and without $\mathrm{Cl}^{-}$.

$\mathrm{Ni}$ and its oxide is well known to be stable essentially even in aqueous solutions containing $\mathrm{Cl}^{-}$ ions as well as Co. So, focusing on a long time stable use independent of presence and absence of $\mathrm{Cl}^{-}$ions, we have attempted to prepare mixed oxide electrodes consisted of $\mathrm{Ni}, \mathrm{Co}$ and La. Another type of mixed oxide, $\mathrm{Ag}-\mathrm{Ni}-\mathrm{Co}$, was also prepared to compare with the catalytic activity for OER on the La-Ni-Co. In this paper, a method of preparing the oxide electrode from oxide powder without PTFE binder and some results on the catalytic activity obtained mainly in alkaline solution are given, along with a little results in $\mathrm{Cl}^{-}$containing solutions.

\section{EXPERIMENTALS}

Mixed oxide powders were prepared by freezedrying in vacuum of mixed hydroxide suspension casted on inside wall of a flask cooled, which being coprecipitated from a mixed $\mathrm{Ni}, \mathrm{Co}$ and $\mathrm{La}$ or $\mathrm{Ag}$ nitrate solution by $\mathrm{NaOH}$ aq addition, followed by calcinating at $100 \sim 1000^{\circ} \mathrm{C}$ for $5 \mathrm{hr}$ in air. The mixing ratio between them, Ni:Co:La or $\mathrm{Ag}$, was

\footnotetext{
Faculty of Science, Science University of Tokyo (1-3 Kagurazaka, Shinjuku-ku, Tokyo 162)

†KOBELCO (Kinugaoka, Mooka-shi, Tochigi 321-43)

$\dagger$ † Dowa Mining CO.,LTD ( Hachioji-shi, Tokyo 192)

Key words: OER electrode, Ni-Co oxide
}

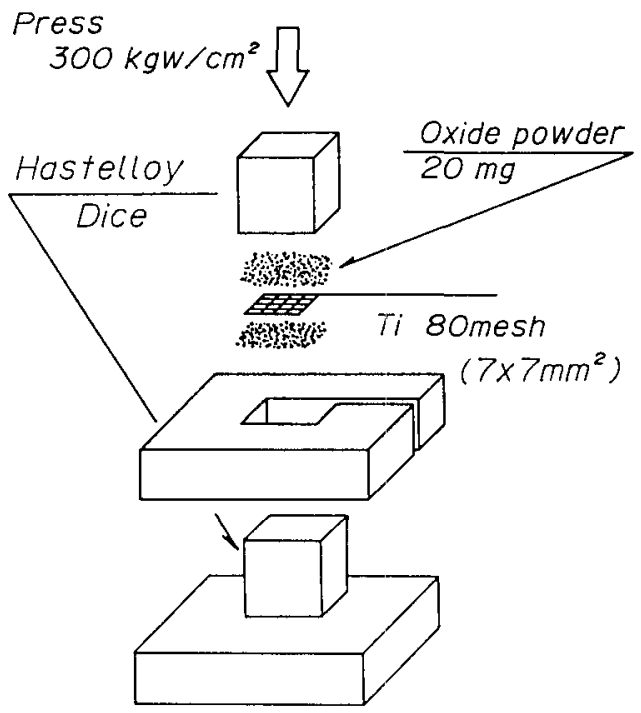

Fig. 1 Schematic illustration of electrode preparation by compressing oxide powder.

$1: 2:(0 \sim 2.0)$ in mole. Finally, the oxide electrodes were made by compressing the oxide powder with. out any binder on both sides of a Ti net ( 80 mesh, $7 \times 7 \mathrm{~mm}^{2}$ ) between two Hastelloy dice, as shown in Fig. 1.

The performance of the oxide electrodes for the oxygen evolution reaction was evaluated on the potentiostatic measurements basically in $0.1 \sim 8.0$ $\mathrm{mol} / \mathrm{dm}^{3} \mathrm{KOH}$ solutions in nitrogen atmosphere. That is, the dependence of the catalytic activity on the content of foreign elements ( $\mathrm{La}, \mathrm{Ag}$ ) was studied from the current density at a constant overpotential, based on steady state polarization curves. Also, the dependence of the current and the potential on $\mathrm{KOH}$ concentration was similarly investigated. XRD and XPS were applicd respectively to determine the structure and to identify the oxidation state of the constituent metallic cations of the electrodes. 


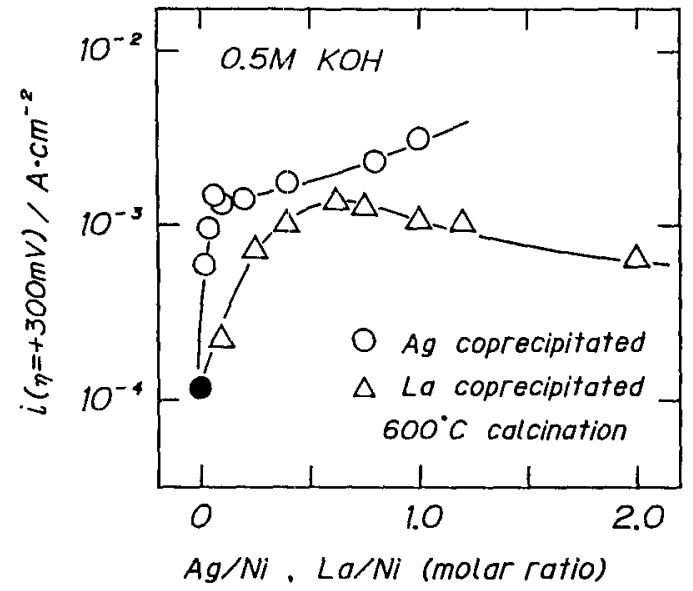

Fig. 2 Dependence of catalytic activity for OER on the content of foreign elements.

\section{RESULTS AND DISCUSSION}

3.1 Characteristic of the compressed oxide electrodes

When a solid electrode would be made of powder, PTFE binder is used in many cases. Although the binder is excellent as the adhesion and repellent, disadvantages of bringing different surface area each time and adhesion of large gas bubbles exist to meet with a difficulty not to obtain quantitative data. But, by adopting the oxide electrode made by compressing powder between Hastelloy dice with higher hardness, it was found that good reproducible data as shown in Fig. 2 could be obtained and smaller oxygen bubbles generated homogeneously over the surface.

To evaluate the catalytic activity and the chemical stability of the oxide electrodes, they were exposed to prolonged electrolysis in $8.0 \mathrm{~mol} / \mathrm{dm}^{3}$ $\mathrm{KOH}$ solution at a constant overvoltage. The current was confirmed to be kept constant without any spalling of powder for all electrodes for $72 \mathrm{hr}$.

\subsection{Catalytic activity}

Fig. 2 represents dependence of the current density observed in $0.5 \mathrm{~mol} / \mathrm{dm}^{3} \mathrm{KOH}$ at an overvoltage of $+300 \mathrm{mV}$ upon the molar ratio of foreign cations $(\mathrm{La}, \mathrm{Ag})$ coprecipitated into the $\mathrm{Ni}$-Co oxide. The activity increases linearly with increase of La content to 0.2 in the molar ratio in the case of La coprecipitation. A ratio of $\mathrm{La} / \mathrm{Ni}=0.625$ gave the maximum activity, after which the activity decreases slightly to reach a constant value. In the case of Ag precipitation, the addition of smaller Ag content $(\sim 0.10$ in the molar ratio) enhances markedly the activity compared with that of La, followed by raising slightly the activity with the increase of $\mathrm{Ag}$ content above 0.10 molar ratio. On the other hand, the activity on oxide powder electrodes typically depends on the calcination temperature of the oxide/hydroxide. The optimum calcination temperature was concluded from our detailed examinations to be 150,300 and $600^{\circ} \mathrm{C}$ : respectively for the $\mathrm{NiCO}_{2} \mathrm{O}_{4}$, the oxide containing $0.08 \mathrm{Ag}$ in the molar ratio and that containing $0.625 \mathrm{La}$.

Tafel slope and reaction order for the $\mathrm{Ag}$ containing oxide in $0.1 \sim 8.0 \mathrm{~mol} / \mathrm{dm}^{3} \mathrm{KOH}$ solutions were $60 \mathrm{mV} /$ decade and 1 respectively, being almost the same as those for the La containing one in $\mathrm{KOH}$ solutions below $1.0 \mathrm{~mol} / \mathrm{dm}^{3}$. These Tafel slope and reaction order were independent of the calcination temperature. But they were different from $40 \mathrm{mV} /$ decade and 2 for the $\mathrm{NiCO}_{2} \mathrm{O}_{4}$ electrode. These facts suggest to take different mechanism for OER between the $\mathrm{NiCO}_{2} \mathrm{O}_{4}$ and the $\mathrm{Ag}$ or La containing electrode in lower concentration of $\mathrm{KOH}$.

The electrolysis in alkaline solutions containing $0.4 \mathrm{~mol} / \mathrm{dm}^{3} \mathrm{KCl}$ was also made on the La containing electrodes, to investigate whether the catalytic activity is affected by $\mathrm{Cl}^{-}$and whether $\mathrm{Cl}_{2}$ evolutes. It was found that the Tafel slope and the exchange current were not affected by $\mathrm{Cl}^{-}$. At the same time, $\mathrm{Cl}_{2}$ evolution was not observed in the Tafel region $\left(0.1 \sim 1 \mathrm{~mA} / \mathrm{cm}^{2}\right)$.

From the cyclic voltammetry in $\mathrm{Fe}$ (III)/ Fe(II) solution, XPS and XRD analyses, it could be considered that extremely fine particles of metallic $\mathrm{Ni}$ as the active site were dispersed in some surface layers of the La containing oxide electrode, by which the catalytic activity being enhanced along with the creation of higher oxide state $\left(\mathrm{Ni}^{3+}, \mathrm{Co}^{3+}\right)$.

Details of the structure and the surface composition of the electrodes will be reported together with mechanism of OER in a following paper.

\section{References}

[1] J.O'M.Bockris, and T.Otagawa, J. Electrochem. Soc., 131, 290, (1984).

[2] A.Wattiaux, and J.C.Grenier, ibid, 134, 1714, (1987).

[3] P.Rasiyah, and A.C.C. Tseung, ibid, 129 , $1724,(1982)$.

[4] P.Rasiyah, and A.C.C. Tseung, ibid, 130, 2384, (1983).

[5] J.C.Botejue Nadesan, and A.C.C. Tseung, ibid, 132, 2957, (1985). 